\section{Basic biology of Drosophila}

\section{Peter Lawrence}

The Genetics and Biology of Drosophila. Vols 2a, 2b and 2c. Edited by $M$. Ashburner and T.R.F. Wright. (Academic: London, New York and San Francisco, 1979.) Vol. 2a: £28.50, \$59; Vol. 2b: $£ 29.60, \$ 61.25$. Vol. 2c: $£ 32, \$ 74$.

ASHBURNER and Wright is a mammoth read. Or is it? This is the question for the Drosophila worker: Are the three parts of this volume a handbook for reference or a collection of ephemeral reviews for reading? If the former then the Drosophilist will want to buy them (or, rather, prefer to beg or steal them as they cost nearly $£ 90$ ). If the latter, then a lending library can be relied on and the relevant chapters read. It is not clear what the editors would have their books be. They write that it is an attempt "to gather together as much information on the basic biology of Drosophila as possible excluding only its formal genetics found in volume 1 and its population biology to be covered in volume 3 "'.

I think these books deserve to be judged by high standards and to me that means as a handbook, a book which no Drosophila worker can be without because it contains the basic facts and methods. A handbook should make accessible the present state of hard knowledge, where the literature is critically distilled and not merely catalogued. This is especially true with Drosophila where an indexed bibliography is available. Just as important, the methods, hints, tricks and ploys should be given special emphasis. In brief, the chapters of a handbook should be written with the readers' needs in mind. By contrast, in reviews, the author is frequently thinking of making some kind of a sale.

As these three books have, necessarily, been written by many authors, it is no surprise that this purpose is not achieved by all, or even by most. Some chapters are, and will be, extremely useful - others are already out of date or just forgettable. The useful or essential chapters are mixed up with the relatively useless ones; the topics are also randomly assorted. This means, of course, that we have to buy each volume even if we need only a small part of each. For example, to obtain the critical review on chromosome puffing the cytologist has to pay for what is in effect a 150 page monograph on behaviour - this topic is unlikely to be close to his, or her, heart. One wonders whether this is one reason why big multiauthor books are becoming so popular with publishers - a small number of desirable pages can sell a larger number of undesirable ones. Always true of journals but not, in the good old days, true of books.

As I read through volume 2 it was not always easy to discern editorial purpose. The chapters are often of profligate and arbitrary length. Why, for example, should we have the same number of pages $(100)$ on mutants which produce tumours (at the moment a somewhat unclear and peripheral subject for most Drosophilists) as on the central technical matter of chromosome aberrations (Volume 1)? Why so much on the field of imaginal disc interesting, but it is moving just too fast to be reviewed at such length in a handbook. Thus, because of long publication delays, the chapters on this topic are already becoming obsolete (from the literature references I get the impression that they were written about 3 years ago). By contrast, the scanning electron microscope atlas of the fly will be useful to many and retain its usefulness for years. The collation of culture methods is admirable and here one can detect the special atmosphere of free exchange of know-how and stocks, which development and its genetics? This field is

is such a pleasing aspect of work with the fruitfly.

In these books there are chapters on all manner of things: culture methods, both of flies and cells; nutrition; enzyme genetics; visual physiology; behaviour; tumours; chromosome puffing; the blood system; muscles; the fat body; malpighian tubules; ageing; embryonic development; imaginal discs and transdetermination. This means that every fly worker will want to read some parts and others will need to have the books within easy reach of their microscope. However, one cannot help feeling how much better they could have been. The chapters could have been more logically grouped. Ephemera could have been more conscientiously avoided. If the authors had been limited to numbers of pages which correlated with the importance of their subject, could this volume not have been at once shorter, cheaper and more valuable?

Peter Lawrence is on the staff of the MRC Laboratory of Molecular Biology, Cambridge, UK.

\section{Mechanisms of cell killing by radiation}

\section{J.H. Hendry}

Cellular Radiobiology. By Tikvah Alper. Pp.320. (Cambridge University Press: Cambridge and New York, 1979.) Hardback £18; paperback £5.95.

THIS book would be more aptly titled 'Mechanisms in Cellular Radiobiology' or more specifically 'Mechanisms of Cell Killing by Radiation'. Written by one of the leading and often controversial figures in this field for a quarter of a century, the book traces in depth, both historically and scientifically, our knowledge of how various radiations cause a loss of reproductive integrity of cells when irradiated in different conditions.

It is the only book in recent years to compare and contrast fully and with clarity the response of different cell types from bacteria to mammalian cells, and it is this comparison which has provided much of our insight into the mechanisms of radiobiological effects. As the latter have not yet been fully elucidated, this has prompted hypotheses such as target theory and repair models to 'explain' dose-response relationships. These are discussed at length both in the first few and in the last few chapters. Sandwiched in between are the observations concerning dosage modifications caused by radiosensitisers (primarily oxygen), radioprotectors, ionisation density, phase of the cell cycle at which cells are irradiated, dose fractionation, and dose-rate effects.

The failure of target theory to accommodate certain critical radiobiological findings has led to the clear conversion of the author from target theory to repair-type models which are less rigid in their constraints. Perhaps as a consequence the correlation between chromosomal injury and cell lethality, now convincingly demonstrated, receives little attention. The treatise of repair-type or pool models is novel and comprehensive.

The book concludes with a chapter on measurements of cell survival in vivo, which is purposefully concise but which is consequently not as comprehensive as the other chapters. Also, in a few instances, effects are discussed which have not generally been found by other investigators, for example, aspects of survival and

Although there are many useful tables of collated data, this is clearly not simply a textbook for learning by rote. It is more a stimulating thesis to be digested, argued, even attacked, and will undoubtedly remain a firm favourite with mechanistic radiobiologists. In contrast to nearly all other specialised texts, the provision of a volume within everyone's pocket. Radiobiology in the Paterson Laboratories at the Christie Hospital and Holt Radium Institute, Manchester, UK. dose-rate effects in bone marrow. separate paperback edition puts this

J.H. Hendry is Head of the Department of 